\title{
Os direitos na relação de cuidado com pessoas idosas em contexto de lar
}

\author{
The rights in the care relationship in elderly home
}

Sandra Patrícia Custódio Baptista Elvas ${ }^{1}$

\begin{abstract}
Resumo
Os assistentes sociais no desenvolvimento da relação de cuidado com pessoas idosas integradas em lar, têm como objetivo o bem-estar, a dignidade e os direitos. Esta relação de cuidado transporta para valores e princípios éticos, na garantia efetiva da dignidade e direitos das pessoas idosas. O presente artigo, trata da relação de cuidado desenvolvida pelos assistentes socias com pessoas idosas integradas em lar, numa abordagem qualitativa, através de pesquisa documental, de modo a ampliar o debate sobre o desenvolvimento da relação de cuidado, partindo da ética, da dignidade e dos direitos das pessoas idosas integradas em lar. Toda a relação de cuidado deve desenvolver-se assente em valores éticos, na autodeterminação, no poder de decisão, na individualização, na dignidade e no respeito. Através desta atuação desenvolve-se a capacitação, a tomada de decisão livre, a garantia do respeito das convicções, necessidades e privacidade. Os direitos, vontades e gostos das pessoas idosas, ainda são invisíveis na relação de cuidado, pelo que existe a necessidade de serem uma prática efetiva.
\end{abstract}

Palavras-Chave: dignidade, direitos, relação, cuidado, idosos.

\begin{abstract}
Social workers in the development of the care relationship with elderly people integrated in elderly home, aim at well-being, dignity and rights. This care relationship transports to ethical values and principles, in the effective guarantee of the dignity and rights of the elderly. This article deals with the care relationship developed by social workers with elderly people integrated in elderly home, in a qualitative approach, through documentary research, in order to broaden the debate on the development of the care relationship, starting from ethics, dignity and the rights of elderly people integrated into the home. Every care relationship must develop based on values, self-determination, decision-making power, individualization, dignity and respect. Through this action, training is developed, free decision-making, the guarantee of respect for convictions, needs and privacy. The rights, desires and tastes of the elderly are still invisible in the care relationship, so there is a need to be an effective practice.
\end{abstract}

Keyword: dignity, rights, relationship, care, elderly.

\footnotetext{
${ }^{1}$ Santa Casa da Misericórdia de Lisboa; CLISSIS - Centro Lusíada de Investigação em Serviço Social e Intervenção Social | E-mail: sandra.baptista@scml.pt
} 


\section{Introdução ${ }^{2}$}

A dignidade é um conceito ético, a consciência de si próprio e a relação com os outros, são duas vertentes que vão criando o conceito de Dignidade Humana, sendo que a consciência de si, se começa a construir na infância (CNECV, 1999).

O Conselho Nacional de Ética para as Ciências da Vida (1999), no documento Reflexão Ética sobre a Dignidade Humana, refere a dignidade humana enquanto conceito evolutivo, dinâmico e abrangente, associando a ética do cuidado, do ponto de vista histórico com "as mulheres na cultura ocidental, nas suas práticas quotidianas do cuidado dos vulneráveis da sociedade (...) as crianças, os idosos, os doentes, os deficientes” (p. 6). Segundo Banks (2015) "Ethics is about how human beings treat each other and the ecosystem. It covers matters of rights, responsibilities and well-being” (p. 2).

Agich (2007) faz uma reflexão crítica às práticas de instituições de longa permanência nos Estados Unidos, abordando a violação dos direitos básicos no que respeita: à associação, ao receber visitas e a poder partilhar atividades com os amigos fora da instituição. Esta violação de direitos enquadra a ausência de dignidade.

O compromisso com a dignidade humana é um valor amplamente compartilhado, é a reivindicação de que todos os seres humanos sejam tratados com respeito (Chapman, 2011). Contudo, o termo dignidade humana pode transmitir uma multiplicidade de entendimentos. Os cuidados centrados na pessoa devem enquadrar um modelo de cuidados que permita capacitar a pessoa para o seu próprio processo de cuidados e vivência numa instituição. O modelo de cuidados capacitador, é um modelo que tem por base a intervenção centrada na pessoa, assente numa filosofia de gestão de serviços humanizada. Este modelo baseia-se nos princípios e valores éticos do Serviço Social assentes na dignidade humana. As pessoas idosas, pretendem tomar decisões sobre a sua vida, assumindo assim o controle sobre a sua vida, ficando para trás, serviços normatizados, tradicionais e paternalistas

Os serviços adquirirem uma maior aceitação por parte das pessoas idosas se forem delineados com elas. Nesta assunção é necessário ter a noção, de que na arena da intervenção diária as pessoas idosas muitas vezes são pessoas fragilizadas, sendo fundamental trabalhar de forma acessível e visível a sua cidadania, a autodeterminação e o poder de decisão, com base num modus operandi instituído na organização (Luz, 2018).

\footnotetext{
${ }^{2}$ Este artigo reporta parte da investigação, relativa à tese de doutoramento que a autora está a desenvolver, associada ao tema, o assistente social na gestão de lar para pessoas idosas: a humanização na relação de cuidado.
} 
Payne (2011) dá enfase ao serviço social humanístico enquanto prática de cuidado numa vertente holística, onde a prestação de cuidados se reveste de questões éticas, onde o cuidador pode exercer sobre a pessoa cuidada um lugar de controlo de poder. O cuidado não é um ato isolado, encontra-se inserido num contexto envolto num sistema com diversas influências e variantes, e que principalmente é feito por pessoas, que consoante os seus valores, assim o farão.

Em todo o desenvolvimento da relação de cuidado os valores que devem estar associados são: a autodeterminação, o poder de decisão, a individualização, a dignidade da pessoa, o respeito pela pessoa "que representa a liberdade de escolha e de participar na vida social" (Carvalho, 2016, p. 76), a tomada de decisão sobre a sua vida e sobre a sua vontade de ser respeitada.

\section{Envelhecimento: Cuidado e Ética}

O cuidado é um conceito holístico e multidimensional, este encontra-se em todas as dimensões da vida, todas as pessoas precisam de ser cuidadas desde a nascença, contudo, o cuidado não se encontra somente associado à sobrevivência biológica, este encontra-se igualmente relacionado com as questões sociais, relações interpessoais, com a cultura (Payne, 2009), com as emoções e com o bem-estar. O cuidado encontra-se, assim, intrínsecamente relacionado com a existência humana, este emerge do ser na preservação da vida, sendo "una forma de estar en el mundo, en la relación consigo mismo, y con los otros se logra la trascendencia, entre más conoce la persona su existencia como ser y la hace consciente, mayor es su actitud respecto al cuidado" (Ramírez-Pérez, Cárdenas-Jiménez e Rodríguez-Jiménez, 2015, pp. 150-151).

Para Gil (2020), o cuidado reveste-se de "duas dimensões: uma relacional e uma outra que abarca os aspetos instrumentais ou técnicos, «o fazer»» (p. 67). Cuidar significa dar apoio em atividades que a pessoa sozinha já não consegue realizar, sendo atividades da vida diária (higiene corporal, mobilidade física, apoio na alimentação, entre outras), assim como, as atividades instrumentais da vida diária (fazer compras, preparar refeições, tratar da roupa, usar o dinheiro, usar transportes ou deslocar-se sozinha, entre outras), apoio emocional e suporte. Havendo uma trajetória de cuidar que se encontra relacionada com os acontecimentos e sentimentos no decorrer dos cuidados (São José, 2012).

O processo de cuidar encontra-se envolvido num contexto complexo, com diversas variantes, associando aspetos positivos ou negativos que se encontram relacionados com a forma como o cuidador foi cuidado (Mafra, 2011). 
Segundo Harris e White (2018) no dicionário Social Work \& Social Care, o termo cuidado em serviço social "usually refers to the act or process of looking after people by undertaking tasks that they are unable to do for themselves" (p. 55). Os autores consideram que os assistentes sociais têm a capacidade de conferir ao tema do cuidado uma conotação menos negativa, deixando de ser associado à dependência como fator de discriminação e opressão.

A ética tem o propósito de refletir o agir humano, a ação humana e de compreender os critérios e valores que orientam a realização dessas ações,

A ética, no seu sentido mais amplo, é a ciência da moral e arte de dirigir a conduta.

De forma geral, a ética é o conjunto de permissão e de interdições que têm um enorme valor na vida dos indivíduos e em que estes se inspiram para guiar a sua conduta (Fortin, 2009, p. 114).

A ética é universal, "o respeito pela vida é condição sine qua non para o desenvolvimento de todo o trabalho relacionado com os Direitos humanos. A importância da vida (...) é a fonte inspiradora de todos os restantes ideais e valores" (ONU, 1999, p. 30), a vida é inviolável. Tem como intuito aprimorar o homem através da ação e por isso procura que as suas ações se movam segundo a integridade, harmonizando as ações com a verdade ou o bem. Assim, poder-se-á entender a ética como uma praxis que racionaliza a conduta humana, e faculta princípios, normas e valores para a ação, que o homem irá utilizar, de uma forma progressiva e questionando em permanência quais serão as soluções mais adequadas para os dilemas que se colocam (Menezes, 2016, p. 162).

A ética respeita a conduta humana, ao ser em socialização e convivência com os outros, em sociedade, é neste contexto de vivências, de forças, de poder, de interações que atua o Serviço Social. Estes contextos complexos de intervenção em constante mudança, numa sociedade que muda a um "ritmo acelerado, onde cada situação nova aparece do nada, e quando aparece, já sabemos que não pode durar muito tempo, porque será, uma vez mais, substituída" (Carvalho, 2016, p. IX).

O serviço social tem vindo a "construir-se a par com o desenvolvimento económico e social, da integração dos direitos humanos e da democracia participativa (...) a profissão passou a estar relacionada com os valores dos direitos humanos, capacitação e empowerment" (Carvalho, 2016, p. 38).

Carvalho (2011) refere que "a ética deve conciliar a autonomia (justiça) e a relação (cuidado). Na ética da responsabilidade social, estas duas dimensões não devem ser 
descuradas" (p. 241). A responsabilidade social encontra-se associada à solidariedade, à proteção e à defesa da liberdade individual do sujeito, no Serviço Social a responsabilidade social "tem uma importância crucial (...) O exercício da ética na acção do Serviço Social parte do princípio de que todos os seres humanos têm uma dimensão ética que implica o respeito, a tolerância, a aceitação do ser humano" (ibidem, pp. 241244). Considerando que, a ética ocupa um lugar de grande destaque na relação de cuidado com as pessoas idosas, no seu conjunto deve equacionar-se a ética do cuidado, a responsabilidade social e a solidariedade nas interações dentro da organização social.

Boff (1999) afirma que "cuidar é mais que um ato; é uma atitude” (p. 12). Fazer do envelhecimento um processo de direitos e de humanização é uma responsabilidade social, uma obrigação coletiva, sendo um marco fundamental o desenvolvimento desta prática nas instituições que prestam cuidados e promovem o bem-estar.

Assente na declaração da Federação Internacional dos Assistentes Sociais, o Serviço Social é a profissão dos direitos humanos, e tem nesta relação com os direitos humanos, a base dos valores e princípios, para Carvalho (2016) "os valores éticos em Serviço Social são únicos e fundamentais para o exercício profissional” (p. 89). Em 1988 a Federação Internacional dos Assistentes Sociais declara o serviço social como uma profissão dos direitos humanos, não obstante a sua intervenção já ser anteriormente compatível com a defesa dos direitos humanos, desde as pioneiras do Serviço Social, Jane Addams, Mary Richmond, Alice Saloman e Bertha Reynolds (Carvalho, 2016).

Toda a intervenção desenvolvida, baseada em valores e princípios requer uma série de competências fundamentais para potenciar a intervenção sobre os papéis que os assistentes sociais devem desempenhar na tomada de decisões e na prática em contextos organizacionais. Desenvolver uma intervenção ética e um agir ético requer uma reflexividade crítica, tendo consciência dos contextos de intervenção, do seu papel e poder (Banks, 2015).

Quando falamos em ética no serviço social, pretende-se destacar "uma visão dinâmica, uma ética teleológica, com um propósito, uma ética reflexiva e uma ética reconstrutiva que possa ser aplicada à ação humana" (Carvalho, 2016, p. 48), assim, a ética baseia-se em princípios gerais do dever e do bem-estar, tendo como princípios: dever, liberdade, razão prática, justiça, responsabilidade jurídica, respeito, boa vontade, felicidade, utilidade, e com princípios de caracter nas relações, a ética do cuidado e do olhar (Carvalho, 2016). 
Em Portugal, o atual código deontológico do serviço social foi aprovado pela Associação de Profissionais de Serviço Social em outubro de 2018. Os valores éticos podem ser "definidos como o conjunto de características de uma determinada pessoa ou organização, que determinam a forma como a pessoa ou organização se comporta e interage com outros indivíduos e com o meio ambiente" (Carvalho, 2016, p. 73). A ética da justiça reflete-se na ética do compromisso, da solidariedade e da tolerância, estando o assistente social ativo na discussão e mediação, podendo assim contribuir para os direitos humanos e para a justiça social (Tomé, 1999).

A ética do cuidado baseia-se numa ética feminista, as limitações associadas ao desenvolvimento das mulheres, considerando a sua preocupação com os sentimentos e relacionamentos, inteligência emocional e racional, passaram a ser vantagens humanas, cuidar é uma ética humana é o que os seres humanos fazem (Gilligan, 2013).

O processo de cuidar e de crescimento são intrínsecos aos valores morais, as responsabilidades e compromissos que derivam das relações externas ao processo de cuidar. Este processo encontra-se eticamente relacionado com empatia, para Zoboli (2004) "cuidar de alguém é prestar-lhe atenção" (p. 25), escutar de forma atenta ajuda o outro a falar, libertando-o para a sua alteridade. A relação de cuidado é uma "relação de respeito pressupõe uma abertura para o contato, escuta, descoberta do diferente do que eu sou, domino e conheço" (Cherix e Júnior, 2017, p. 585). A pessoa que cuida torna-se ouvinte, sendo uma caixa-de-ressonância na qual o outro se liberta, exteriorizando as suas necessidades, o seu eu, este necessita esvaziar-se, expondo-se à disposição do outro sem reservas, sendo considerada outra máxima da ética, a escuta. Só a escuta cria laços e mediação entre os homens, de modo, a que estes configurem uma comunidade, a escuta devolve a cada um o que é seu (Han, 2018).

A intervenção do assistente social em lar pode ser mais impactante, mais marcante, atendendo à transição que a pessoa faz do seu domicílio para uma estrutura institucional, considerada como um alojamento coletivo. Esta transição poderá ter na pessoa uma influência mais ou menos perturbadora e desenraizadora, como refere Faleiros (2013) "a pessoa que chega ao estabelecimento pode ser destituída da conceção que tem de si mesma, de sua autoestima, sendo possível ocorrer, nas instituições totais, uma série de rebaixamentos, degradações, humilhações e profanações do eu" (p. 84). Nesta senda, o grupo Global Alliance for the Rights of Older People (GAROP, 2015), refere que as pessoas idosas por si auscultadas, consideram existir um maior risco de verem os seus direitos violados, quando estão integradas em instituições. Deve o Serviço Social 
contribuir para o desenvolvimento de práticas anti idadistas e anti opressivas. Nesta senda o grupo European Ageing Network (EAN, 2019), alude que não existe um investimento efetivo em cuidados promotores de qualidade de vida e bem-estar, sendo inaceitável existirem lógicas de desvalorização das pessoas idosas assentes na discriminação.

Para Faleiros (2013) "cuidar (...) significa assegurar a autonomia, reverter as discriminações, desenvolver a autonomia, inclui os sujeitos em serviços e direitos, como propõe, aliás, a visão humanizadora" (p. 84). A intervenção social tem como foco a pessoa, não sendo a pessoa considerada só, integrando-a numa dimensão social e coletiva num sistema cultural com valores, e caraterísticas políticas e económicas, vivendo numa determinada época.

A ética enquanto fator intrínseco ao Serviço Social foi evoluindo ao longo dos tempos, a par com a profissão. No âmbito das instituições da prestação de cuidados, fica claro que só com uma prestação de cuidados com valores e princípios é possível desenvolver uma prestação com qualidade. O cuidado tem evoluído e tem sido abordado de diversas formas, contribuindo para as orientações éticas e comportamentos morais.

Num estudo feito por Braga, Bestetti e Franco (2016), com recurso a entrevistas semiestruturadas a pessoas idosas a residir em lar, quer privado quer público, os autores concluíram, que para estas pessoas o conforto no lar privado e público, se encontra relacionado com as necessidades que estão na base da pirâmide, relacionando o conforto na sua maioria, com o não passar por necessidades.

O papel do assistente social nas instituições é garantir que os direitos das pessoas, o seu bem-estar e a sua qualidade de vida se encontram garantidos, nesta perspetiva encontra-se imbuído todo um quadro ético que se reflete na responsabilidade da qualificação de quem presta cuidados, potenciando o cuidado além das necessidades fisiológicas.

\section{Humanização e Relação de Cuidado Em Lar}

As organizações prestadoras de serviços humanos são serviços reflexivos, o seu planeamento, a intervenção, o trabalho de equipa espelha a conceção que o gestor e a equipa têm dos residentes (Payne, 2002).

Nesta assunção importa ter em conta que o trabalho desenvolvido em equipa é fundamental para a humanização dos cuidados, a transmissão da missão e dos valores organizacionais, e principalmente a filosofia de gestão do serviço onde se encontra imbuída a missão e os valores organizacionais, tendo em consideração que a um nível 
mais micro o objetivo são as pessoas e a humanização dos cuidados na sua vertente holística, no livro verde sobre o envelhecimento (2021) encontra-se espelhada a necessidade de "garantir a dignidade pessoal, a escolha, o bem-estar" (p. 19) das pessoas idosas. É com base na transmissão dos valores, dos direitos e da dignidade da pessoa que se desenvolve a relação e o respeito pelo outro, sendo neste espaço que a gestão realizada pelo assistente social se torna relevante. A formação de Serviço Social do ponto de vista da sua matriz, baseada na sua identidade histórica constitui-se como uma profissão bastante eclética, focada no reconhecimento da dignidade e no valor inerente à pessoa (Washburn e Grossman, 2017), constitui-se assim, como uma profissão privilegiada para assegurar as responsabilidades da direção técnica, em serviços que seguem uma filosofia de humanização de serviços e de dignidade da pessoa idosa.

Thompson e Thompson (2001) apresentam uma reflexão em torno do modelo do cuidado, considerando que o modelo tradicional do cuidado assenta num princípio medicalizado, que foca a doença e a vulnerabilidade da velhice, arguindo que as pessoas são meros destinatários de cuidados. Devendo este modelo ser alterado para um modelo de capacitação conferindo às pessoas um olhar de direitos e de dignidade, sendo que este modelo aborda a autodeterminação e o poder de decisão de quem necessita de cuidados.

A intervenção passa por proporcionar espaço para as pessoas poderem decidir e participarem no seu processo, numa lógica de continuidade. O modelo de cuidados na atualidade e na perspetiva da intervenção do assistente social é um modelo de cuidados que visa a capacitação através da parceria com a pessoa, para o apoio na tomada de decisão e para que esta se sinta livre na tomada de decisão e na partilha. Na perspetiva da capacitação e empoderamento permite combater abordagens idadistas, sendo que estes preconceitos podem ser um fator de bloqueio ao desenvolvimento de um modelo de cuidados capacitador.

A humanização dos serviços e da relação de cuidado requerem uma liderança cultural de aceitação do outro, o trabalho desenvolvido com a equipa e pela equipa, pode ser uma das barreiras ao desenvolvimento de um modelo de cuidados capacitador, tendo os profissionais que demonstrar habilidades e competências para o reconhecimento de que a pessoa que necessita de cuidados, tem direito a poder viver uma vida o mais normal possível, nas suas vivencias do dia-a-dia, podendo optar pelas suas preferências e gostos. Wilson (2007) no seu estudo, refere que a abordagem de cuidado centrada no relacionamento, deu maior oportunidade ao desenvolvimento da participação das pessoas idosas, quer nos seus cuidados, quer nas vivências da comunidade do lar. 
Segundo Carvalho (2016) "é necessário introduzir humanidade na competência técnica", a autora questiona como é possível em instituição - Lar, ser resposta "às inquietações, questões da vida, de sentido, de sofrimento?” (p. 266) e responde à sua questão referindo que a resposta está na "humanização do cuidado, do serviço" (p. 266).

A complexidade do serviço social humanístico, considera a pessoa como um todo, intervindo na complexidade da humanidade, na sua interação com o meio social, deste modo, não é possível seguir normas tradicionais e padronizadas. Vieira (2018) refere que as normas e prescrições excessivas submetem os profissionais a atuações padronizadas, retiram o fator da humanização do contexto da gestão, liderança e intervenção. A humanização dos serviços através de práticas humanísticas requer uma relação e conexão entre as pessoas, assim, cuidar desenvolve-se através de uma relação entre os profissionais, os residentes e outras pessoas. As pessoas idosas enquanto cidadãos tem o direito de contribuir para as mudanças na organização (Payne, 2012). O modelo de cuidados centrado na pessoa permite concretizar um plano de cuidados holístico, que tem por base a participação do residente e da equipa (Payne, 2009).

Para Rodriguez (2011) a intervenção centrada na pessoa é um modelo de atenção à pessoa, que tem como princípio, tratar as pessoas idosas com os mesmos direitos que qualquer pessoa, com o mesmo respeito, com a mesma dignidade. Para os autores Washburn e Grossman (2017) para que o modelo de cuidados centrado na pessoa seja efetivamente concretizado e para que inclua todos os princípios e valores a que o mesmo alude, o paradigma do cuidado terá de mudar, considerando a relação estabelecida entre a pessoa e o assistente social, o centro. A relação de cuidado desenvolvida entre o assistente social e o residente é fundamental para o desenvolvimento do plano de cuidados e de um modelo que preconize a pessoa no centro da relação de cuidado.

\section{Desafio: o lar como casa}

No que respeita ao ambiente do lar, local que passa a ser a casa da pessoa idosa que faz a transição para este novo espaço, onde irá viver e desenvolver as suas relações de convivência, vários autores consideram que este deve ser confortável, ser decorado com pertences dos residentes, respeitando os seus gostos e sendo um espaço com sentido para cada pessoa que lá vive. Para Pereira (2016) “a identidade de lugar é a relação da identidade da pessoa com o lugar, ou seja, a relação entre a pessoa que sou e o lugar" (p. 125), por sua vez Fragoso (2016) refere que o ambiente deve ser acolhedor, de modo que 
permita apoiar o residente no "processo de revisão de vida e na elaboração de projetos e no envolvimento das atividades" (p. 331).

Braga, Bestetti e Franco (2016) consideram o lar como um espaço de múltiplos significados: arquitetónico, moral, de privacidade e individualidade, onde se desenvolvem as vivências e as relações humanas, na manutenção das condições de respeito e de dignidade. $\mathrm{O}$ ambiente e o conforto são dois fatores que se relacionam, interferindo a qualidade de ambos nos estados emocionais, psicológicos, sentimentais e a forma como a pessoa sente o lugar onde vai viver ou onde vive. "Quando falamos em ambiência, pensamos em humanização por meio do equilíbrio de elementos que compõem os espaços, considerando fatores que permitam o protagonismo e a participação" (Bestetti, 2014, p. 602).

No estudo realizado por Braga, Bestetti e Franco (2016), foram realizadas 14 entrevistas semiestruturadas a pessoas idosas a viver em lares públicos e privados, sendo possível aferir que

o maior determinante do conforto são as necessidades sociais e psicológicas, que envolvem: lazer (falta de atividades, tempo ocioso, passeios, inatividade); falta de liberdade (autonomia, perda de identidade, regras); e relacionamentos (moradores e funcionários), familiares, apoio e suporte social. O lazer pode ser considerado como uma atividade não obrigatória de busca pessoal de prazer no tempo livre (p. 14).

É evidenciado pelas pessoas entrevistadas, a ausência de ocupação, levando a sentimentos de inutilidade, o que impacta negativamente nas vivências das pessoas, a ocupação e a possibilidade de desenvolver uma atividade dá a sensação de liberdade, no caso dos passeios, sendo referido neste sentido que "ninguém tem liberdade aqui dentro. A liberdade que se tem, é andar dentro de casa" (p. 15).

Para os autores, estes lares apresentam programas e vivências com excesso de regras e horários pré-definidos, ausentes de flexibilidade, sendo uma rotina mecanizada. Payne (2009) refere que em muitos lares, as pessoas são colocadas sentadas em cadeiras contra a parede e vêm o dia todo televisão, o que considera limitante e com alguma privação.

Os espaços no lar podem ser privados e comuns, constituindo muitas vezes um ambiente de comunidade, as interações são partilhadas, contudo um dos objetivos do lar 
é proporcionar interação, relação e convívio significativo e positivo. Nesta assunção, o conforto das pessoas requer decisões que têm de ser partilhadas, onde se pressupõe uma conexão entre as decisões partilhadas e o conforto. Contudo, Payne (2009), refere que por vezes a única zona privada dentro de um lar é o espaço da administração, que segundo o autor é um ambiente que não se encontra apropriado para a construção de relações.

Hoof et al (2016) desenvolveram uma pesquisa com 27 pessoas idosas a viver em lar, no estudo pretendem avaliar o que as pessoas consideram como conforto, assim as pessoas consideram que na transição para este novo local, as fotografias, pinturas e móveis são considerados objetos de valor sentimental. Os autores consideram que estes objetos podem desenvolver sensações com um impacto positivo. A televisão é valorizada pela sua função prática, sendo referido pelos entrevistados que é a forma como passam o dia e mantêm contato com o mundo, "residents indicated that watching television is the most common way of spending the day and combating boredom" (p. 7). Foi igualmente referido por algumas pessoas entrevistadas que não se sentiam em casa, independentemente dos pertences que possam levar. Algumas pessoas referiram não poder levar pertences devido ao espaço dos quartos e porque os profissionais necessitam de espaço para se poderem movimentar. Deste modo foi identificado pelos residentes, que espaços maiores potenciam o conforto na possibilidade de poderem levar alguns pertencem e fazerem espaços mais aconchegantes nos locais onde vão passar a viver, considerando que este é igualmente um espaço onde recebem as visitas. É ainda evidenciado no estudo a necessidade de privacidade, mais quartos individuais referindo, que as cores dos quartos poderiam ser alteradas ao seu gosto para serem mais acolhedoras.

Dijck-Heinen et al (2014) realizaram um estudo onde analisaram o que as pessoas idosas integradas em lar consideram como verdadeiro lar, a questão é, se é sentido como um verdadeiro lar. Os autores referem que existe um equilíbrio que tem de ser alcançado entre diversos fatores para que possa existir um "true sense of home" (p. 57). Dos resultados do estudo, construíram um modelo de sentido de casa, com base nas respostas das dez pessoas entrevistadas, destas 10 pessoas, 4 viviam em lar, 6 tinham vivido em processo de reabilitação, estando naquele momento a residir nas suas casas com serviços ao domicílio. Assim as pessoas referiram que a "sense of home was not only related to the physical environment, but to the total ecosystem of the nursing home" (p. 61), tendo os temas mais evidenciados sido: segurança e proteção, relacionamentos e ações, cuidado e vivência. 
Segundo Estevam de Silva et al (2020), "uma ambiência equilibrada propicia um espaço físico amigável e promove encontros de qualidade, criando subjetividades positivas e estimulantes" (p. 417).

Os direitos das pessoas idosas integradas em lar encontram-se referidos no Conselho Nacional de Ética para as Ciências da Vida (2014), que refere que os idosos devem ter a possibilidade de:

- Participar na decisão que determina quando e a que ritmo tem lugar a retirada da vida ativa;

- Viver em ambientes que sejam seguros e adaptáveis às suas preferências pessoais e capacidades em transformação, proporcionem proteção, reabilitação e estimulação social e mental numa atmosfera humana e segura;

- Gozar os direitos humanos e liberdades fundamentais, quando residam em qualquer lar ou instituição de assistência ou tratamento, incluindo a garantia do pleno respeito da sua dignidade, convicções, necessidades e privacidade e do direito de tomar decisões acerca do seu cuidado e da qualidade das suas vidas;

- Ter acesso aos recursos educativos, culturais, espirituais e recreativos da sociedade;

- Viver com dignidade e segurança, sem serem explorados ou maltratados física ou mentalmente.

Do estudo realizado por Cruz (2014) a 178 profissionais a trabalhar na resposta social de lar, a autora refere que o estudo evidenciou por parte dos profissionais, pouca relevância da decisão das pessoas idosas, nas escolhas das atividades, na divulgação de aspetos da sua vida privada e na prestação de informações esclarecidas sobre saúde. Considerando que o conceito de dignidade nos cuidados conjuga variáveis interligadas, com a autonomia, a motivação, o envolvimento, a privacidade, participação efetiva, a intimidade e privacidade, a liberdade, o direito ao sigilo, a confiança e segurança na equipa.

\section{Conclusão}

O apoio no acesso aos serviços, à cidadania e a todos os direitos que enquadram e envolvem a relação de cuidado, são pontos fulcrais da relação de cuidado, proporcionando à pessoa idosa o direito à participação ativa, no seu projeto de vida, na residência e na comunidade, independentemente da sua condição de saúde. A garantia efetiva dos direitos, da autodeterminação, da liberdade e da atenção focada na pessoa deve ser uma 
realidade visível. Permanece a necessidade da construção de respostas que sejam adequadas às pessoas, e não pessoas que tenham de se moldar aos serviços existentes.

Os assistentes sociais devem estar cientes da necessidade de ter uma prática anti opressiva combatendo a indiferença, as omissões, as restrições e o excesso de regras, a falta de recursos humanos, a falta de tempo para a prestação de cuidados, considerando tudo isto uma ameaça à dignidade das pessoas. Deve existir um compromisso ético, que prime pelos cuidados individualizados, diferenciados e respeitosos, "É preciso que haja um afastamento das abordagens atuais enraizadas em tradições antigas e seja reconhecida a individualidade do idoso residente numa unidade que agora é sua casa e na qual deve decidir" (Cruz, 2014, p. 45).

Os direitos das pessoas idosas que se encontram integradas em lar, o direito a serem tratadas com dignidade no desenvolvimento da relação de cuidado, é um princípio ético que deve ser prática diária na intervenção do assistente social em lar, quer na intervenção direta quer na liderança e gestão de respostas sociais dirigidas às pessoas idosas.

\section{Referências bibliográficas}

Agich, G. (2007). Reflections on the Function of Dignity in the Context of Caring for Old People. Journal of Medicine and Philosophy, 32(5), 483-494. http:// https://doi.org/10.1080/03605310701626455.

Associação dos Profissionais de Serviço Social. (2018). Código Deontológico dos Assistentes Sociais. http://www.apss.pt/.>

Banks, S. (2015). Social Work Ethics. International Encyclopedia of the Social \& Behavioral Sciences, 22,782-788. https://doi.org/10.1016/B978-0-08-097086-8.28030-6.

Bestetti, M. (2014). Ambiência: espaço físico e comportamento. Rev. Bras. Geriatr. Gerontol., 17(3), 601-610. http://dx.doi.org/10.1590/1809-9823.2014.13083 Vozes.

Boff, L. (1999). Saber Cuidar Ética do humano - compaixão pela terra. Editora

Braga, A.; Bestetti, M.; Franco, F. (2016). O Conforto na Ambiência de Idosos Moradores em Instituições de Longa Permanência. Revista Kairós Gerontologia, 19(2), 327-347. https://revistas.pucsp.br/kairos

Carvalho, M. (2011). Ética, Serviço Social e "Responsabilidade Social": o caso das pessoas idosas. R. Katál., Florianópolis, 14(2), 239-245. https://www.scielo.br/

Carvalho, M. (2014). Serviço Social e Intervenção com Idosos: Desafios Atuais. In M. Carvalho \& C. Pinto (Eds.), Serviço Social Teoria e Prática (pp. 421-436). Pactor.

Carvalho, M. (2016). Ética Aplicada ao Serviço Social - Dilemas e Práticas Profissionais. Pactor.

Chapman, A. (2011). Human Dignity, Bioethics, and Human Rights. Amsterdam Law Forum, 3. https://ssrn.com/abstract=1762549 
Cherix, K., \& Júnior, N. (2017). The care of elderly as a field of inter-subjective relations: ethic reflections. Interface, 21(62), 579-88. https://doi.org/10.1590/1807$\underline{57622015.0492}$

Cruz, S. (2014). A Dignidade em Lares de Idosos [Master's thesis, Instituto Superior de Serviço Social do Porto]. Repositório Institucional do Instituto Superior de Serviço Social do Porto. https://comum.rcaap.pt/

Comissão Europeia (2021). O Livro Verde sobre o Envelhecimento. Bruxelas Comissão Europeia. https://epale.ec.europa.eu/

Conselho Nacional de Ética para as Ciências da Vida. (1999). Reflexão Ética Sobre a Dignidade Humana. Documento de Trabalho 26/CNECV/99. htpps://www.cnecv.pt.

Conselho Nacional de Ética para as Ciências da Vida. (2014). Parecer sobre as vulnerabilidades das pessoas idosas, em especial das que residem em instituições. 80/CNECV/2014. htpps://www.cnecv.pt

Dijck-Heinen, C., Wouters. E., Janssen. B., Hoof. J. (2014). A Sense Of Home Through The Eyes Of Nursing Home Residents. International Journal for Innovative Research in Science \& Technology, 01(04), 57-69. http://www.ijirst.org/

Estevam da Silva, N., Nascimento, M., Bestetti, M. (2020). Ambiência em instituições de longa permanência para idosos: rumo a uma visão mais abrangente da $\begin{array}{llll}\text { literatura. } & \text { Revista } & \text { Kairós-Gerontologia, 23(2), 417-434. }\end{array}$ http://dx.doi.org/10.23925/2176-901X.2020v23i2p417-434>.

European Aging Network. (2019). Long Term Care 2030. 2 ed. European Aging Network. https://www.ean.care/.

Faleiros, V. (2013). Desafios de cuidar em Serviço Social: uma perspectiva crítica. Rev. Katálysis, 16, 83-91. https://doi.org/10.1590/S1414-49802013000300006

Federação Internacional dos Assistentes Sociais. https://www.ifsw.org

Fortin, M. (2009). O Processo de Investigação da concepção à realização. (5a ed.). Décarie Éditeur.

Fragoso, V. (2008). Humanização dos cuidados a prestar ao idoso institucionalizado. Revista IGT, 5(8), 51-61. http://www.igt.psc.br

Gil, A. (2020). Estruturas residenciais para pessoas idosas: Relação entre qualidade dos cuidados e qualidade do emprego. Cidades, Comunidades e Territórios, 40 (6), 6787. https://doi.org/10.15847/cct.jun2020.040.doss.art05.

Global Alliance for the Rights of Older People. (2015). What older people say about discrimination and human rights in older age: A consultation by the Global Alliance for the Rights of Older People. GAROP. https://ifa.ngo/.

Han, B. (2018). A Expulsão do Outro. Relógio D’Água Editores.

Luz, H. (2017). Empoderamento Organizacional e intervenção social. In P. Albuquerque, \& A. Arcoverde (Eds.), Serviço Social Contemporâneo - reflexividade e estratégia. (pp. 91-114). Pactor.

Gething, L., Fethney, J., McKee, K., Goff, M., Churchward, M., Matthews, S. (2002) Knowledge, Stereotyping and Attitudes Towards Self Ageing. Australasian $\begin{array}{llll}\text { Journal on Ageing, 74-79. } & \text { 21(2), }\end{array}$ https://onlinelibrary.wiley.com/doi/pdf/10.1111/j.1741-6612.2002.tb00421.x 
Harris, J., White, V. (2018). Dictionary of Social Work \& Social Care. (2 nd). Oxford University Press

Hoof, J., Wetzels, M., Dooremalen, A., Nieboer, M., Gorkom, P., Eyck, ZwertsVerhelst, E., Peek, S., Voort, S., Moonen, M., Dijck-Heinen, C., Weffers, H., Overdiep, R., Aarts, S., Vissers-Luijcks C. \& Wouters, E. (2014) The Essential Elements for a Nursing Home According to Stakeholders from Healthcare and Technology: Perspectives from Multiple Simultaneous Monodisciplinary Workshops. Journal of Housing For the Elderly, 28(4), 329-356. https://10.1080/02763893.2014.930365

Mafra, S. (2011). A Tarefa do Cuidar e as Expectativas Sociais Diante de um Envelhecimento Demográfico: a importância de ressignificar o papel da família. Rev. Bras. Geriat. Gerontol, 14(2), 353-363. htpps://doi.org/10.1590/S1809$\underline{98232011000200015 .}$.

Menezes, N. (2016). Ética e Deontologia: Os construtos de uma prática reflexiva. In C. Moura (Eds.), Novas Competências para Novas Exigências no Cuidar. (pp.161172). Euedito.

Organização das Nações Unidas. (1991). Princípios Das Nações Unidas Para As Pessoas Idosas. Resolução 46/91 da Assembleia Geral das Nações Unidas. https://gddc.ministeriopublico.pt/

Organização das Nações Unidas. (1999). Direitos Humanos e Serviço Social. Departamento Editorial do ISSS. https://gddc.ministeriopublico.pt/

Payne, M. (2002). Management. In R. Adams, L. Dominelli \& M. Payne (Eds.). Critical Practice in Social Work (pp. 223-243). Palgrave Macmillan.

Payne, M. (2011). PAYNE, Malcolm - Humanistic Social Work-Core Principles in Practice. Palgrave and Macmillan.

Payne, M. (2012). Citizenship Social Work with older people. Policy Press.

Pereira, M. (2016). Ambiente Saudável em Contexto Organizacional. In C. Moura (Eds.), Novas Competências para Novas Exigências no Cuidar. (pp.123-131). Euedito.

Ramírez-Pérez, M., Cárdenas-Jiménez, M. \& Rodríguez-Jiménez, S. (2015). El Dasein de los Cuidados desde la Fenomenología Hermenéutica de Martín Heidegger. Enfermería Universitaria. 12(3), 144-151. https://doi.org/10.1016/j.reu.2015.07.003

Ribeirinho, C. (2013). Serviço Social Gerontológico: Contextos e Práticas Profissionais. In M. Carvalho (Eds.), Serviço Social no Envelhecimento. (pp. 177-200) Pactor.

São José, J. (2012). Entre a gratificação e a opressão: os significados das trajetórias de cuidar de um familiar idoso Sociologia. Revista da Faculdade de Letras da Universidade do Porto, 2, 123-150. https://www.redalyc.org/

Tomé, M. (1999). Ética e Deontologia para o Serviço Social. Revista Intervenção Social. 19, 47-54. http://repositorio.ulusiada.pt/

Thompson, N. \& Thompson, S. (2001). Empowering Older People Beyond the Care Model. Journal of Social Work, 1(1), 61-76. http://DOI: 10.1177/146801730100100105.

Vieira, P. (2018). Pensar a excelência nas organizações sociais. Vida Económica. 
Washburn, A. \& Grossman, M. (2017). Being with a Person in Our Care: PersonCentered Social Work Practice that is Authentically Person-Centered. Journal of Gerontological Social Work, 60(5), 408-423, https://10.1080/01634372.2017.1348419

Wilson, B. (2007). Exploring Relationship in Care homes: a constructivist inquiry. [Doctoral dissertation, Universidade de Sheffield]. http://etheses.whiterose.ac.uk/

Zoboli, E. (2004). A redescoberta da ética do cuidado: o foco e a ênfase nas relações. Revista da Escola de Enfermagem da USP, 38, 21-7. https://www.scielo.br/scielo 